\title{
ANÁLISE DA UMIDADE RELATIVA DO AR NO ENTORNO PRÓXIMO AO RESERVATÓRIO DA USINA HIDRELÉTRICA DE DONA FRANCISCA, EM AGUDO-RS EM PERÍODO DE VERÃO E INVERNO
}

\author{
Ismael Luiz Hoppe ${ }^{(\mathrm{a})}$, Cassio Arthur Wollmann ${ }^{(\mathrm{b})}$, Iago Turba Costa ${ }^{(\mathrm{c})}$ Aline Nunes da Silva ${ }^{(\mathrm{d})}$ \\ (a) Ismael Luiz Hoppe, Mestrando em Geografia, Universidade Federal de Santa Maria - UFSM, \\ ismael.hoppe@hotmail.com \\ (b) Cássio Arthur Wollmann, Professor do Programa de Pos-Graduação em Geografia (PPGGEO) e Departamento \\ de Geociências, Universidade Federal de Santa Maria - UFSM, cassio_geo@yahoo.com.br \\ ${ }^{(c)}$ Iago Turba Costa, graduando em geografia Licenciatura Plena, Universidade Federal de Santa Maria - UFSM, \\ iagoturba@hotmail.com \\ (d) Aline Nunes da Silva, graduando em geografia Bacharelado, Universidade Federal de Santa Maria - UFSM, \\ alinendeca@hotmail.com
}

\section{Eixo: CLIMATOLOGIA EM DIFERENTES NÍVEIS ESCALARES: MUDANÇAS E VARIABILIDADES}

\begin{abstract}
Resumo
O presente artigo teve como objetivo analisar a umidade relativa do ar durante os períodos de verão e inverno do ano de 2014 em dois pontos distintos, em escala mensal, no entorno próximo da represa da Usina Hidrelétrica de Dona Francisca, localizada no município de Agudo / RS. O ponto mais próximo encontra-se a uma distância de $1,41 \mathrm{~km}$ da margem do lago e o ponto mais distante do lado está a $3,83 \mathrm{~km}$. Nessa pesquisa foram utilizados abrigos meteorológicos de baixo custo, para a coleta dos dados. Através do estudo foi possível notar que a umidade relativa do ar variou de acordo com os fatores climáticos advindos da paisagem e uso do solo de cada localidade, assim como dependente da estação predominante em cada período do ano de 2014.
\end{abstract}

Palavras chave: Umidade Relativa do Ar, Usina Hidrelétrica, verão, Inverno, Lago Artificial.

\section{Introdução}

Durante o século $\mathrm{XX}$, inúmeras represas foram construídas pelo mundo visando satisfazer a crescente demanda por água e energia. Considerada como símbolo de modernização e da habilidade humana em controlar e utilizar recursos da natureza, a construção de grandes represas cresceu consideravelmente entre as décadas de 1930 e 1970 (CMR, 2000).

Atualmente, na comunidade geográfica, discute-se se a presença de um grande volume de água represado poderia afetar o clima local, alterando os elementos climáticos, tais como a umidade relativa do ar e a temperatura no entorno destes lugares, podendo levar até influências nos totais pluviométricos.

Considerando os estudos em climatologia e as alterações climáticas, quando percebidas, essas podem ser devido aos processos naturais ou forças externas, ou às mudanças persistentes causadas pela ação do homem na composição da atmosfera ou do uso da terra. Não poderia ser diferente com a umidade relativa do ar, que é um elemento atmosférico que exerce influências sobre as temperaturas, as chuvas e na sensação térmica (VAREJÃO, 2006). 


\section{OS DESAFIOS DA GEOGRAFIA FÍSICA NA FRONTEIRA DO CONHECIMENTO \\ Instituto de Geociências - Unicamp \\ Campinas - SP \\ 28 de Junho à 02 de Julho de 2017}

A umidade relativa do ar pode ser considerada como a relação de água existente no ar e o valor máximo que poderia haver na mesma temperatura, sofrendo influência desta. Isto quer dizer que se a temperatura variar, a umidade pode variar também, e ambas são inversamente proporcionais. (AYOADE, 2002).

Com relação à umidade relativa do ar no Rio Grande do Sul, Sartori (2003) aponta que esta varia em média, de $75 \%$ a $85 \%$. Ainda, a umidade no Estado é estável durante as diferentes estações do ano; no verão e na primavera os valores ficam em torno de $68 \%$ a $85 \%$, ao passo que no inverno os valores encontram-se entre $76 \%$ e $90 \%$.

A área de estudo está localizada no extremo norte do município de Agudo, no distrito de Nova Boêmia, na região central do Rio Grande do Sul. Encontra-se inserida na Microrregião de Restinga Seca e na Mesorregião do Centro Ocidental Rio-Grandense, a qual pertence à Quarta Colônia de Imigração Italiana (IBGE,2015). O município encontra-se a uma distância de 250 km de Porto Alegre, capital do Estado do Rio Grande do Sul, e a $70 \mathrm{~km}$ de Santa Maria e sua área total é de 536,1 km (Figura 1).

Neri (2009, apud BIDOME, 1989) afirma que a área de abrangência do estudo e da usina situa-se na zona de transição entre as regiões fisiográficas Encosta Inferior do Nordeste e Depressão Central, região de relevo acidentado, passando de forte ondulado e montanhoso para suave ondulado e plano.

Segundo o Instituto Brasileiro de Geografia e Estatística (IBGE, 2017), o clima da região é classificado como subtropical super úmido sem seca, com temperaturas médias entre $10{ }^{\circ} \mathrm{C}$ a $15{ }^{\circ} \mathrm{C}$. As temperaturas na área de estudo, bem como no Estado do Rio Grande do Sul variam conforme as estações do ano. Em períodos de inverno a temperatura média fica entorno de $10^{\circ} \mathrm{C}$ a $15^{\circ} \mathrm{C}$, as médias mínimas ficam entre $6^{\circ}$ e $10{ }^{\circ} \mathrm{C}$ e nos verões a temperatura média é superior a $22^{\circ} \mathrm{C}$, a médias das máximas varia entre os $28^{\circ} \mathrm{C}$ e $30^{\circ} \mathrm{C}$. Essa amplitude térmica se dá pela entrada de energia solar entre os solstícios e os equinócios e pela atuação das massas de ar sobre a região. A umidade relativa do ar varia entre 70\% e 85\%, sendo que nos verões é menor e nos invernos maior (SARTORI, 2003).

A área de estudo faz divisa somente entre os municípios de Agudo e Nova Palma e enquadra-se entre as coordenadas de $29^{\circ} 37^{\prime} 53^{\prime \prime}$ e $29^{\circ} 33^{\prime} 12^{\prime \prime}$ de latitude sul e $53^{\circ} 15^{\prime} 33^{\prime \prime}$ e $53^{\circ} 12^{\prime} 05^{\prime \prime}$ de longitude Oeste, conforme é mostrado na Figura 01. 


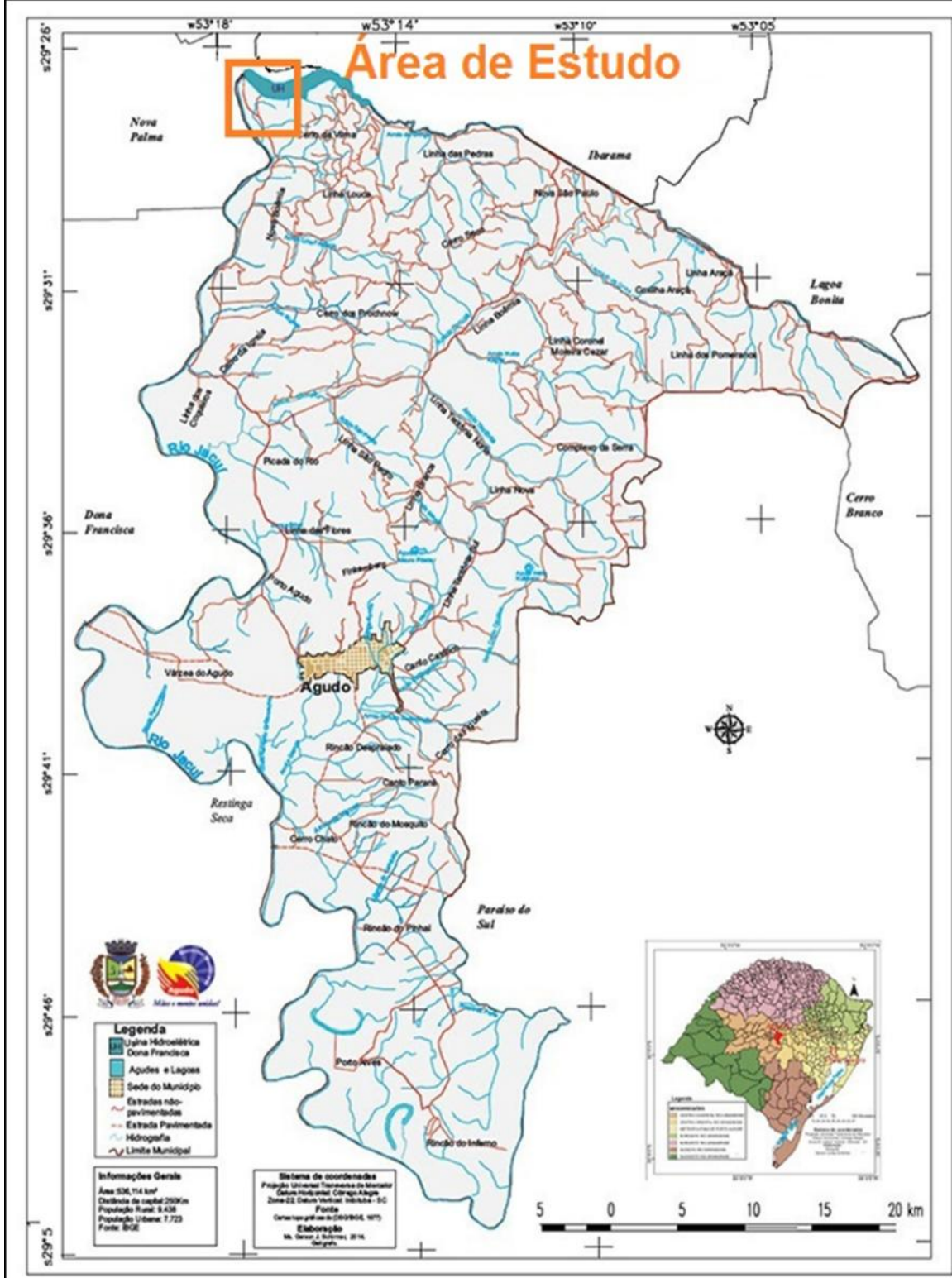

Figura 01: Mapa político administrativo do município de Agudo - RS e localização da área de estudo. Fonte: Prefeitura Municipal de Agudo (Disponível em http://www.agudo.rs.gov.br).

Com isso, o presente artigo teve como objetivo analisar a variabilidade da umidade relativa do ar durante os meses de dezembro, janeiro e fevereiro (período vernal), junho, julho e agosto (período invernal) do ano de 2014 em dois pontos distintos, em escala mensal, no ntorno da represa da Usina Hidrelétrica de Dona Francisca, localizada no município de Agudo / RS.

\section{Metodologia}

Para o desenvolvimento deste trabalho foram realizadas pesquisas na literatura sobre o tema, seguido da coleta de dados na área. A escolha do tema surgiu devido ao fato de que há pouca ocorrência de trabalhos científicos baseados neste conteúdo no Brasil, e especialmente no Rio Grande do Sul, como verificado na revisão bibliográfica. 


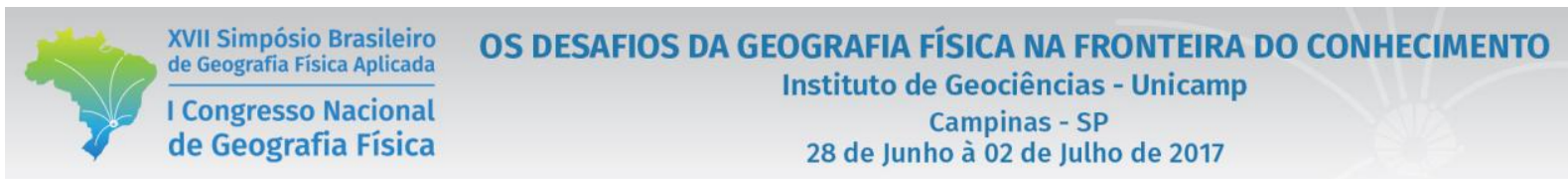

Para a realização da pesquisa foram selecionados dois pontos de amostragem. O ponto 01 está localizado na latitude de $29^{\circ} 29^{\prime} 21^{\prime \prime} \mathrm{S}$ e na Longitude de $53^{\circ} 17^{\prime} 17^{\prime}$ ' $\mathrm{O}$, com altitude de 75 metros acima do nível do mar. Encontra-se a uma distância de 1,41 km da margem do Lago e a 2,42 km do ponto 02 (mais ao sul). O ponto 02 está localizado na longitude de $29^{\circ} 28^{\prime} 36^{\prime \prime} \mathrm{S}$ e na longitude de $53^{\circ}$ 16' 57' O, a uma altitude de 67 metros acima do nível do mar, e uma distância de 3,83 km do lago, conforme a figura 02. Não foi possível instalar um ponto de coleta mais próximo ao lago, pois está área pertence ao Parque Estadual da Quarta Colônia o qual ainda encontra-se em processo de conclusão.
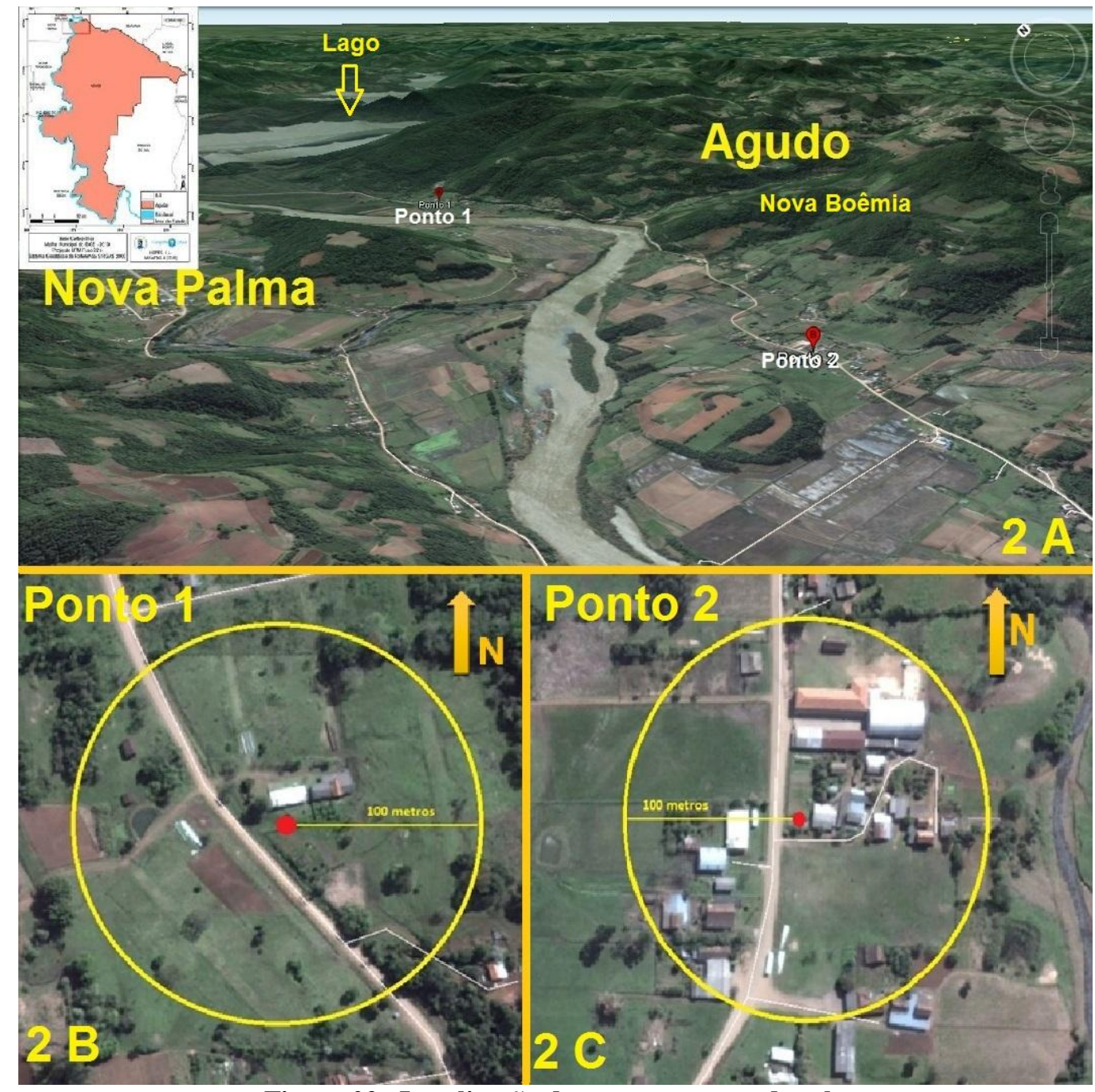

Figura 02 -Localização dos pontos e o uso do solo

2 A: Localização dos Pontos / 2B Uso do solo Ponto 1 / 2 C Uso do Solo Ponto 2

No ponto 01 (Figura 2B), percebe-se uma quantidade considerável de vegetação de grande porte ao seu redor, em um raio de 100 metros, e se localiza mais próxima do reservatório e em maior altitude (74 $\mathrm{m}$ acima do nível do mar) do que o ponto 2 (67 $\mathrm{m}$ acima do nível do mar) (Figura 2C). O lugar também conta com moradias em menor quantidade em seu entorno e uma estrada de terra permitindo o seu acesso, nos 100 metros próximos aos equipamentos o solo é coberto por gramíneas e vegetação rasteira. Observa-se ainda uma pequena parte da área que é usado como lavoura. 


\section{OS DESAFIOS DA GEOGRAFIA FÍSICA NA FRONTEIRA DO CONHECIMENTO \\ Instituto de Geociências - Unicamp \\ Campinas - SP \\ 28 de Junho à 02 de Julho de 2017}

Conforme é possível observar nítida diferença de uso do solo deste ponto de coleta (02) em relação ao ponto 01. A localidade conta com menor cobertura vegetal de grande porte e maior quantidade de residências. Além disso, possui uma estrada de terra que possibilita a passagem de uma circulação considerável de veículos no lugar, bem como lavouras de fumo e a presença de um banhado.

Em um segundo momento foram confeccionados os abrigos meteorológicos de baixo busto proposto por Armani; Galvani (2006) e Milanesi; Galvani (2012), e testado por Hoppe, et. al. (2015). O abrigo meteorológico foi confeccionado com chapas de ferro galvanizado e suas dimensões são $11,5 \mathrm{~cm}$ de altura e $18 \mathrm{~cm}$ de diâmetro, sendo pintado de cor branca; dentro do abrigo foi colocado o Datalogger a 1,5 metros de altura do solo, para fazer a coleta da temperatura e umidade, configurado para realizar coleta automática a cada hora (Figura 03).

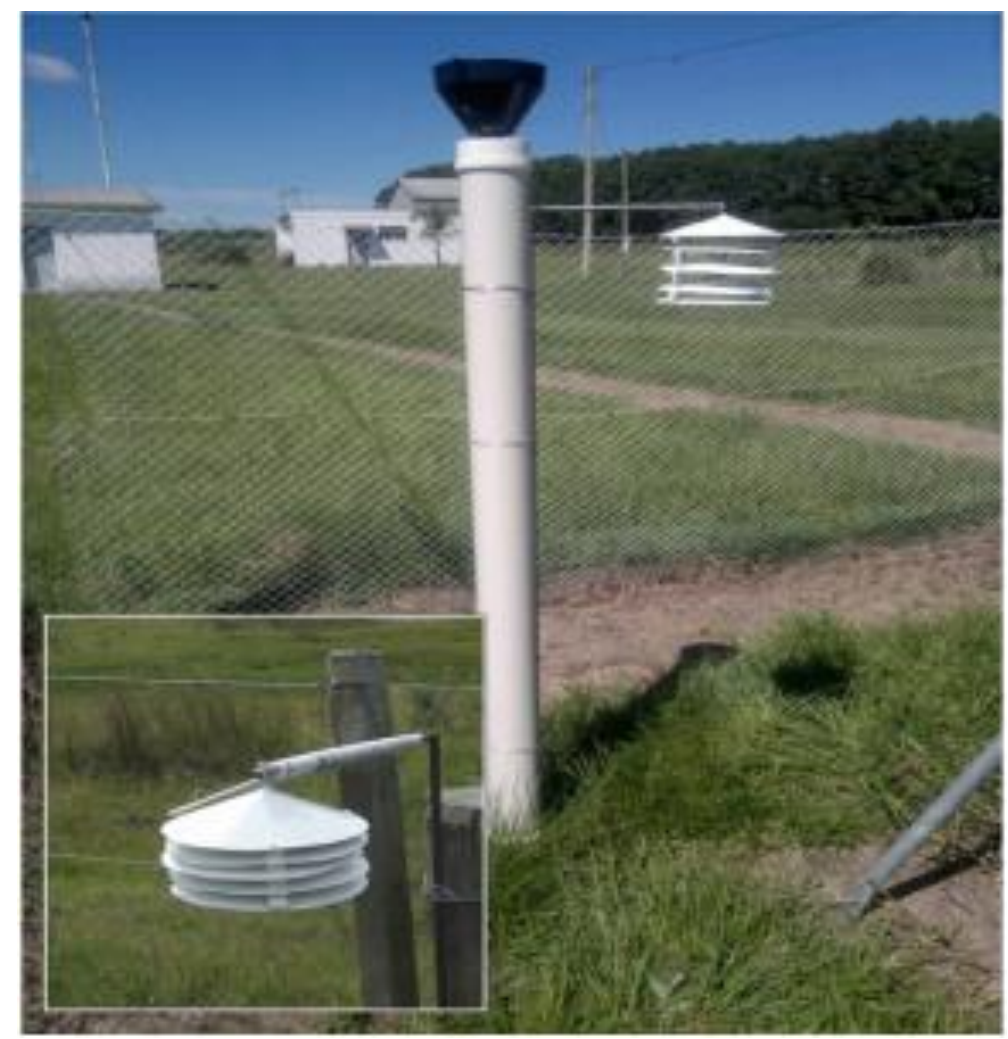

Figura 03 - Abrigo Meteorológico.

Os abrigos foram instalados no dia 16 de dezembro de 2013 e recolhidos no dia 14 de janeiro de 2015 . Para esse trabalho foram usados os dados dos meses de dezembro de 2014, de janeiro de 2014, de fevereiro de 2014 que representam a estação de verão e dos meses de julho de 2014, junho de 2014 e de agosto de 2014, esses meses representam a estação do inverno, conforme propõe Sartori (2003). Os Dataloggers foram configurados para efetuarem registros horários da temperatura do ar durante todos os dias, haja vista a necessidade desse volume de dados para o cálculo correto deste elemento climático e sua variante. 


\section{OS DESAFIOS DA GEOGRAFIA FÍSICA NA FRONTEIRA DO CONHECIMENTO Instituto de Geociências - Unicamp Campinas - SP \\ 28 de Junho à 02 de Julho de 2017}

Após coleta dos dados do Datalogger, foi feito download dos dados e os mesmos foram tabulados em uma planilha do Microsoft Excel 2013. Foram armazenados dados da umidade relativa do ar a cada hora. O primeiro passo foi calcular as médias diárias a fim de calcular-se a média mensal de cada ponto, conforme sugere Wollmann; Simioni; Iensse (2015). Após foi selecionado a umidade mais alta de cada dia e feito a Umidade Máxima absoluta média mensal e a umidades mais baixas para fazer umidade mínima absoluta média mensal. E para se ter a umidade máxima absoluta foi o registro mais alto de cada mês e para obter a umidade absoluta mínima coletou-se o registro mais baixo de cada mês.

As tabelas de análise dos dados foram elaboradas a partir dos dados coletados pelo Datalogger, possibilitando a organização dos valores, e assim encontrar o melhor método de avaliação para conclusão dos resultados. Dentro delas estão contidas informações diárias de um período de aproximadamente um ano, permitindo analisar as medidas obtidas em cada área de estudo (Ponto 01 e Ponto 02).

A partir dos dados tabulados foram construídos gráficos para melhor avaliar e representar as variações da temperatura dos diferentes pontos, sendo resultado dos valores obtidos nas tabelas através da coleta diária de hora em hora pelo Datalogger (umidade relativa do ar).

\section{Discussão do Resultados}

A figura 04 apresenta o gráfico relativo às medições das médias mensais, médias máximas, médias mínimas, absoluta máxima e absoluta mínima da umidade relativa do ar dos meses de dezembro, janeiro e fevereiro (verão). 


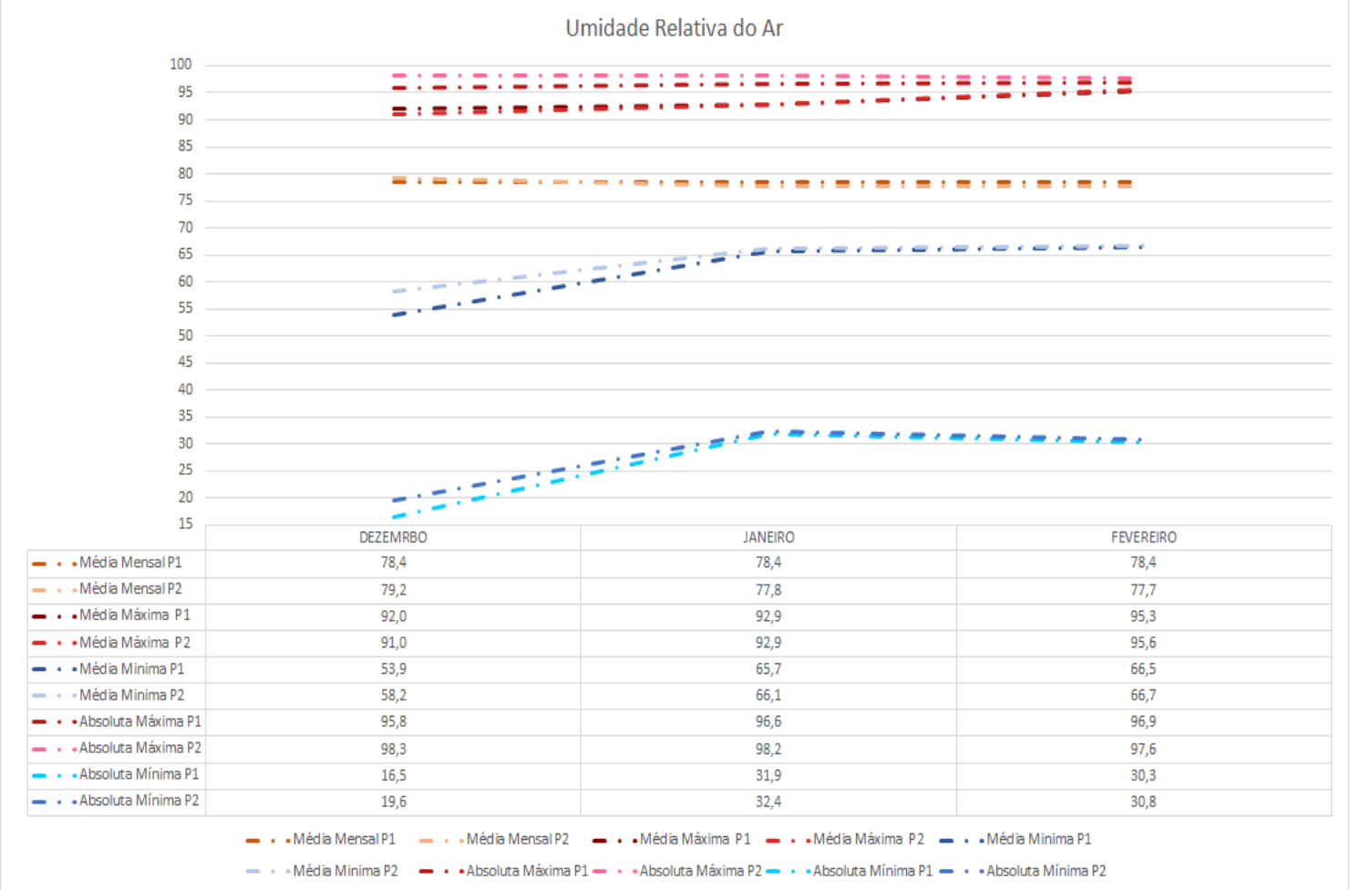

Figura 04 - Gráfico da umidade relativa do ar dos meses de dezembro, janeiro e fevereiro.

Como demonstra o gráfico da imagem 04 a umidade relativa do ar as médias mensais do ponto 01 não ocorreu nem uma variação entre os meses registrando, registrando $78,4 \%$ e o ponto 02 apresenta algumas diferenças entre os meses, dezembro registra $79,2 \%$, em janeiro registra $77,8 \%$ e fevereiro registra $77,7 \%$, para esse período o ponto 02 somente registra as umidades mais elevada do que o ponto 01 em dezembro, para os demais meses o registro foi sempre maior no ponto 02 .

Com relação à média máxima entre os pontos pode observar-se que a umidade relativa do ar não apresenta muita diferença entre os pontos de coletas, no mês de dezembro a uma diferença de $1 \%$, sendo o maior registro no ponto 01 , em janeiro os dois pontos têm o mesmo valor registrado $(92,9 \%)$, e no mês de fevereiro ocorreu uma diferença mínima entre os pontos de $0,3 \%$, no qual o ponto 02 registra o valor mais alto. A média mínima para esse período do ano podemos perceber que o ponto 01 registrou os valores mais baixos para a umidade relativa do ar, em dezembro a diferença entre os pontos foi de $4,3 \%$, a maior diferença entre os pontos, janeiro a diferença foi de $0,4 \%$, e em fevereiro a diferença entre os pontos foi de $0,2 \%$ a menor diferença entre as médias mínimas para esse período.

As umidades absolutas máximas novamente os maiores registros foram no ponto 02 , dezembro a diferença entre os pontos foi de 2,5\%, em janeiro foi de 1,6\% e fevereiro a diferença entre eles foi de $0,7 \%$. As mínimas absolutas registradas para esses meses o ponto 01 registrou os valores mais baixos, e o mais baixo que foi o mês de dezembro que marcou $16,5 \%$ e também registrando a maior diferença entre os pontos entre a umidade mínima absoluta, que foi de $4,1 \%$, nos meses de janeiro e fevereiro a diferença entre os pontos foram de $0,5 \%$, no qual janeiro teve os maiores valores para a mesma. 


\section{OS DESAFIOS DA GEOGRAFIA FÍSICA NA FRONTEIRA DO CONHECIMENTO \\ Instituto de Geociências - Unicamp \\ Campinas - SP \\ 28 de Junho à 02 de Julho de 2017}

A figura 05 apresenta o gráfico relativo às medições das médias mensais, médias máximas, médias mínimas, absoluta máxima e absoluta mínima da umidade relativa do ar dos meses de junho, julho e agosto (inverno).

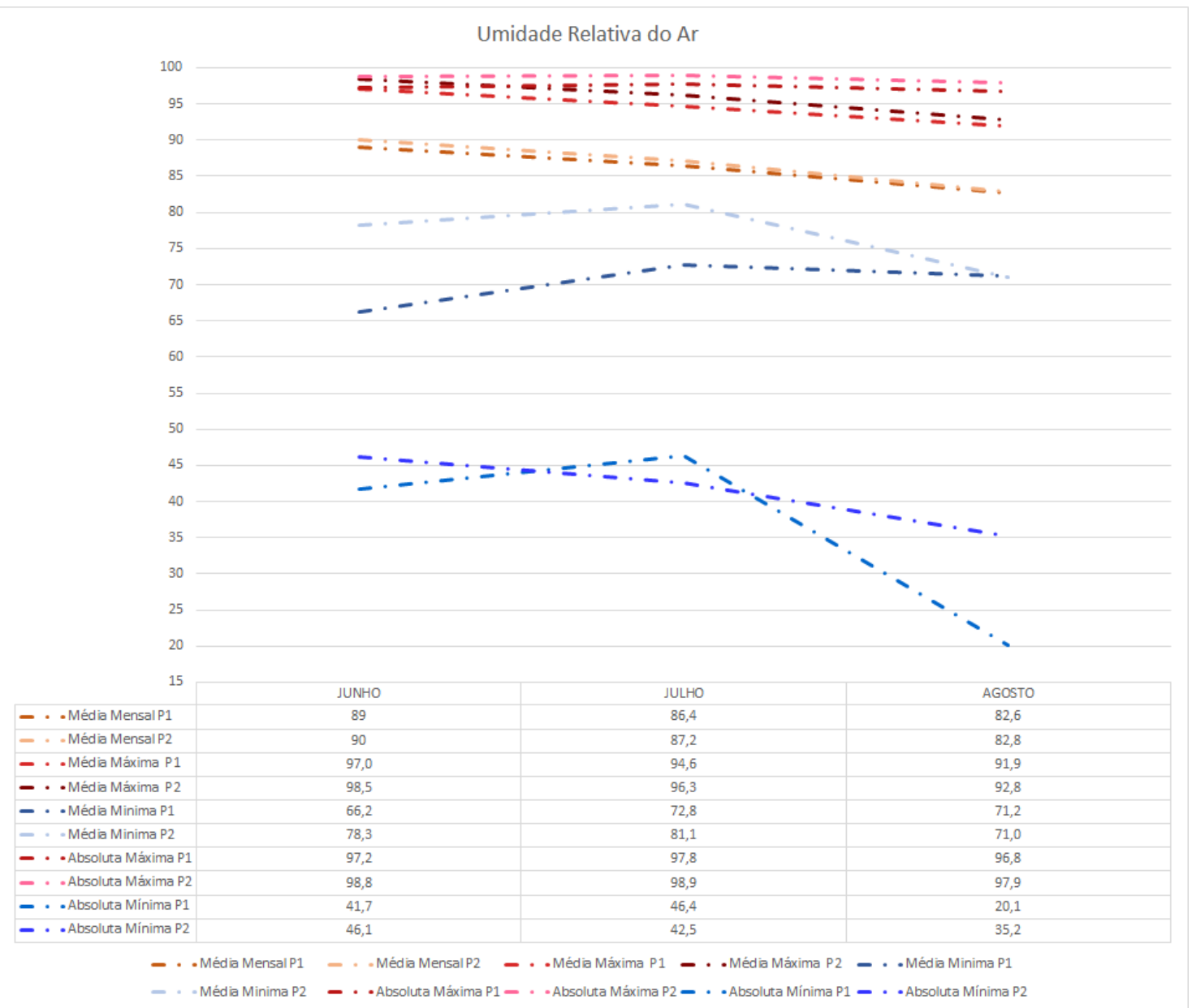

Figura 05 - Gráfico da umidade relativa do ar dos meses de junho, julho e agosto.

De acordo com a figura 05 a umidade média mensal, o ponto 02 sempre registraram mais elevadas em consideração ao ponto 01 , ocorrendo a maior variação no mês de junho registrando uma diferença de $1 \%$, no mês julho a diferença foi de $0,8 \%$, no mês de agosto ocorreu a menor diferença entre os pontos, de $0,3 \%$. Também pode se observar que com o passar dos meses as umidades vão decrescendo. Já as médias máximas para esses meses de inverno novamente o ponto 02 tiveram as umidades mais elevadas em comparação ao ponto 01, registrando diferenças 1,5\% em junho, de 1,7\% em julho e diferença de $0,9 \%$ em agosto, e ainda como pode ser vista no gráfico da imagem 05 , conforme se aproxima da estação do ano (primavera a umidade relativa do ar diminui). Como pode se observar a umidade absoluta mínima média apresentou uma grande variação nos meses de junho e julho, no mês de agosto a diferença entre os pontos foi pequena e neste mês o ponto 02 registrou a menor umidade em comparação ao ponto $01(0,2 \%)$, nos meses de junho e julho o ponto 01 registros os menores valores, em junho a diferença foi de $12,1 \%$ e em julho a diferença entre os pontos foi de $8,3 \%$. 
Umidade do ar absoluta máxima registrada nos meses referente ao inverno não apresentaram grande alterações, sempre registrando o maior dado sempre no ponto 02 , que está mais próximo ao lago, no mês de junho a diferença foi de $1,6 \%$, nos meses de julho e agosto a diferença entre os dois pontos de coleta foi de 1,1\% na umidade relativa do ar. A mínima absoluta para os meses de junho, julho e agosto (período de inverno) os menores registros foram novamente no ponto 02 , que é o mais afastado do lago, nos meses de junho e agosto, no mês de julho ocorreu o inverso, o registro mais baixo de umidade relativa do ar foi no ponto 01, entre as mínimas absolutas registradas entre os pontos pode-se ver no gráfico da imagem 05 que ouve uma variação significativa, no mês de junho a diferença registrada entre os pontos foi de $4,4 \%$, e em julho a diferença é de $3,9 \%$ e em agosto que foi registrada a menor umidade relativa do ar entre os pontos o ponto 01 registrou $20,1 \%$ e o ponto 02 registrou $35,2 \%$ registrando uma diferença entre os pontos de $15,1 \%$ na umidade relativa do ar.

Em geral, a umidade relativa do ar analisada nos dois pontos, encontram-se muito próximas ao longo dos meses analisados e sua amplitude (entre os dois pontos), podem ser considerados não significativos, devido à variação mínima que apresentam de $1,4^{\circ} \mathrm{C}$.

Com relação à umidade absoluta média máxima, os valores do ponto 02 na maioria dos meses do ano supera a do ponto 01 , devido a sua menor temperatura, sendo novamente, os meses de maior umidade os representativos do inverno, apresentando relação inversa à temperatura.

A umidade média mínima do ponto 01 e ponto 02 foram influenciadas não somente pela temperatura, mas principalmente pela paisagem que os cerca. Por exemplo, o ponto 01 apresenta picos de umidade durante um mês de verão, por se localizar mais próximo do reservatório e possuir mais vegetação em seu entorno, contribuindo para o aumento da umidade.

Até o presente momento de análise dos dados desta pesquisa, observou-se de fato, influência do reservatório em seu entorno próximo somente sobre a umidade relativa do ar mínima média, denotando que a construção da usina e criação do lago artificial tende a aumentar os valores dessa variante calculada de umidade relativa do ar, o que corrobora com todas as pesquisas consultadas no referencial teórico.

De acordo com as figuras 04 e 05 a umidade absoluta máxima mensal do ar nos pontos em estudo demonstraram grande variabilidade, não se aproximando em nenhum dos doze meses do ano e com maiores valores do ponto 02 em relação ao ponto 01 . Entre os meses de janeiro e julho, há uma tendência à umidade relativa do ar maior absolutas aproximarem-se (os valores) entre si. Contudo, a umidade do ponto 02 é superior ao do ponto 01 , o que pode estar associado a uma área de banhado próximo à localidade, que também pode interferir e contribuir para o aumento da umidade máxima absoluta, além do seu comportamento inverso à temperatura relativa do ar. 


\section{OS DESAFIOS DA GEOGRAFIA FÍSICA NA FRONTEIRA DO CONHECIMENTO \\ Instituto de Geociências - Unicamp \\ Campinas - SP \\ 28 de Junho à 02 de Julho de 2017}

Por sua vez a umidade relativa do ar mínima absoluta do ponto 01 é maior do que do ponto 02 , por se encontrar mais próximo do reservatório e ter maior área com vegetação de grande porte seu entorno.

\section{Conclusões}

O estudo realizado na área próxima à da Usina Hidrelétrica da represa da Dona Francisca, no distrito rural de Nova Boêmia, no município de Agudo/RS, serviu para verificação de possíveis influências deste corpo hídrico artificial no clima local. Para determinar essa possível influência foram instalados dois abrigos meteorológicos com a finalidade de obter dados da umidade relativa do ar através de Dataloggers colocados em dois pontos próximos ao reservatório, conforme bibliografia consultada e metodologia testada em outras áreas do Brasil.

Além destes fatores, também foram analisados os resultados de acordo com os meses do ano e uso do solo do local, bem como organização espacial dos diferentes pontos. No ponto 1 observou-se menor concentração de moradias bem como, apresenta também maior cobertura vegetal no entorno e localizase mais próximo da barragem, e se encontra em uma altitude poucos metros superior do que a da segunda área avaliada nesta pesquisa. O segundo ponto, por sua vez, tem como características menor cobertura vegetal, maior quantidade de residências e passagem considerável de automóveis, e situa-se mais afastada da represa e em menor altitude com vale menor encaixado do que no ponto 01 , e menor quantidade de vegetação de grande parte no entorno.

Os resultados analisados indicaram que a umidade relativa do ar varia de acordo com os fatores climáticos advindos da paisagem e uso do solo de cada localidade, assim como dependente da estação predominante em cada período do ano. Nos meses do verão, nota-se uma diminuição na umidade relativa do ar, enquanto no inverno ocorre o inverso, aumento da umidade relativa do ar. Contudo, fatores como o relevo e circulação do ar entre os pontos também são relevantes para caracterização do clima local, de modo que afetam a temperatura e umidade relativa do ar das áreas em estudo.

Por fim, dentro da presente pesquisa procurou-se sanar humildemente os estudos de alterações climáticas por lagos artificiais no Brasil, e em especial no Rio Grande do Sul. Não foram encontrados valores significativos que demonstrassem uma significativa influência do reservatório sobre o clima local, observou-se sensível alteração nos valores da umidade relativa absoluta máxima e mínima no ar, corroborando com os resultados de pesquisas semelhantes em outras localidades do Brasil.

Nesse contexto, ainda se fazem necessários futuros estudos mais aprofundados na área, de modo a se compreender a complexidade da dinâmica do clima local destes locais e assim identificar uma possível alteração ocorrida da formação do reservatório da Usina Hidrelétrica de Dona Francisca em Agudo/RS. 


\section{5Bibliografia}

ARMANI, G.; GALVANI, E. Avaliação do desempenho de um abrigo meteorológico de baixo custo. Revista Brasileira de Agrometeorologia, Piracicaba-SP, v. 14, n.1, p. 116-122, 2006

GRIMM, A. M. Meteorologia básica, 1999. Disponível em: <http://fisica.ufpr.br/grimm/aposmeteo/>. Acesso em 10 de janeiro de 2017 ,

HOPPE, I. L.; IENSSE, A. C.; SIMIONI, J. P. D.; WOLlMANN, C. A. Comparação entre um abrigo meteorológico de baixo custo e a estação meteorológica oficial no INMET, em Santa Maria (RS). Ciência e Natura, v. 37, p. 132-137, 2015.

IBGE - INSTITUTO BRASILEIRO DE GEOGRAFIA E ESTATÍSTICA. IBGE Cidade. Dados censitários do município de Agudo/RS. Disponível em: http://www.cidades.ibge.gov.br/xtras/perfil.php?lang=\&codmun=430637\&search=rio-grande-do-sul|dilermandode-aguiar|infograficos:-informacoes-completas. Acesso em 09 de janeiro. 2017.

MACHADO, F. P. Contribuição ao estudo do clima do Rio Grande do Sul. Rio de Janeiro: Serviço Geográfico do IBGE, 1950.

MENDONÇA, S. F; DANNI-OLIVEIRA, I. M. Climatologia noções básicas e climas do Brasil. São Paulo: Oficina de Texto, 2009.

MILANESI, M. A.; GALVANI, E. Pluviômetro Experimental Para Localidades Remotas. In.: Climatologia Aplicada: Resgate aos Estudos de Caso. Galvani, E.; Lima, N. G. B. (Orgs.). Curitiba: Editora CRV, 2012. v. 1. 1 ed. p.192.

NERI, D. B. Efeitos da Implantação da Usina Hidrelétrica Dona Francisca (RS, Brasil) sobre estágios imaturos de odonata (insecta). Dissertação (Mestrado em Biodiversidade Animal) - Universidade Federal de Santa Maria, 2009.

PREFEITURA MUNICIPAL DE AGUDO. Mapa Político-administrativo de Agudo/RS. Disponível em: <http://www.agudo.rs.gov.br/home>. Acesso em 10 de janeiro de 2017.

SARTORI, M. G. B. A dinâmica do Clima do Rio Grande do Sul: indução empírica e conhecimento científico. 2003, Terra Livre, São Paulo, Ano 19 - Vol. I n.20, P 27-49, Jan/jul. 2003

WOllmann, C. A.; SIMIONI, J. P. D.; IENSSE, A. C. Atlas climático da Estação Ecológica do Taim: Contribuição ao estudo do clima em unidades de conservação no Rio Grande do Sul. 1. ed. Santa Maria: O autor. 2015. 300p. 